\title{
Relationship among Antenatal Care Practices and Socioeconomic Factors with Birth Weight of Neonates in Dhaka City
}

\author{
Md Shahab Uddin Howlader* and Md Sabir Hossain \\ Department of Biochemistry and Molecular Biology, Jahangirnagar University, Bangladesh
}

Submission: December 20, 2017 ; Published: January 30, 2018

*Corresponding author: Md. Shahab Uddin Howlader, PhD Research Fellow, Department of Biochemistry and Molecular Biology, Jahangirnagar University, Bangladesh, Email: gpabd17@gmail.com

\begin{abstract}
Low birth weight is a major public health problem in Bangladesh. Care during pregnancy is an important step to deliver healthy baby. This study focused on the relationship between Antenatal Care (ANC) and birth weight of neonates in Dhaka City. Cross sectional analytical study was conducted for this research. Non-probability convenient sampling was used. The survey like study collected data through questionnairebased face-to-face interviews, for lactating mothers who had at least one baby. Information of anthropometric, socioeconomic, ANC and birth weight was collected within January, 2014 to December, 2016. Descriptive as well as inferential statistics were used. Statistical Package for Social Sciences was used to analyze data. Monthly income of 3.8\% family had less than 10000 BDT followed by $26.1 \%$ family had 10000 to 20000 BDT, $24.2 \%$ had 20000 to 30000 BDT, $9.5 \%$ had 30000 to 40000 BDT, $11.3 \%$ had 40000 to 50000 BDT, $13.2 \%$ had 50000 to 60000 BDT and $11.9 \%$ family had more than 60000 BDT. Educational qualification of mother was $46.9 \%$ less than SSC followed by $15.2 \%$ SSC, $22.2 \%$ HSC and $15.8 \%$ graduate or higher. Most of the children had normal birth weight (72.2\%) and 3.5\%, 20.3\%, and 4.0\% had very low birth weight, low birth weight and overweight respectively. Maternal mental stress, satisfaction at pregnancy, initial ANC visit during pregnancy, vaccination status of mother, regular physical checkup, times of physical checkup, taking medicine at pregnancy, taking IFA supplements, frequency of meal per day, maternal age, maternal education, education of father, occupation of father and mother, children nutritional status (MUAC) were significantly associated with birth weight of neonates ( $p$-value $<0.05$ for all factors). Family income and dietary expenditure had highly significant correlation birth weight of neonates. In conclusion, ANC practices were strongly related with birth weight of neonates in Dhaka City.
\end{abstract}

Keywords: Birth weight; ANC practices; Vaccination; Income

\section{Introduction}

Low birth weight (LBW) is a burning public health issue. Globally, approximately $16 \%$ of infants are born weighing less than $2500 \mathrm{~g}$, which represents more than 22 million LBW babies per year [1]. Over $95 \%$ of these infants are born in low-income and middle-income countries. In South Asia, about one quarter (28\%) of all infants is born with LBW. There is a high probability that the incidence of LBW is underestimated as almost $50 \%$ of all newborns are not weighed at birth.1The WHO defines LBW as weight at birth less than $2500 \mathrm{~g}$ irrespective of the gestational age of the infant $[2,3]$. Based on epidemiological observations, infant mortality rate rapidly rises for newborns weighing less than $2500 \mathrm{~g}$ at birth [3]. LBW includes very low birth weight (VLBW; less than 1500g) and extremely low birth weight (ELBW; less than $1000 \mathrm{~g}$ ) infants, who have the highest risk of adverse outcomes $[2,4]$. Studies have found that LBW babies are about 20 times more likely to die in infancy compared to normal birth weight (NBW) babies, and those who survive, share a greater burden of various physical [5]. The resulting health-care expenditures are also higher for the surviving LBW babies [6]. Furthermore, with the demographic change of increased life expectancy at birth in developing countries, children born with LBW can cause an increased economic burden and an increased disease burden $[7,8]$. Other studies have shown several factors to be determinants of LBW and have demonstrated that preventing those factors can help reduce early childhood morbidity and mortality [9]. The determinants of LBW are genetic, constitutional, obstetric, nutritional, related to maternal morbidities in the antenatal period, exposure toxins and drugs, and linked to antenatal care (ANC). Other factors including smoking, maternal age, birth spacing, ANC, anemia, genital infections, maternal ill health, and stress have also been reported [10]. However, socioeconomic status was associated with only extreme cases of LBW $[11,12]$. It has been found in a study that although most socioeconomic factors are associated with pregnancy outcomes, the pattern of association is clear only for LBW [13]. 


\section{Methods and Materials}

The study was a cross sectional analytical study because study was carried out at a single point in a specified time period. Considering time period and resource availability, cross-sectional analytical (to show association and correlation among different variables) hospital based study design was most feasible for this study. Non-probability convenient sampling was used. Data were collected through questionnaire-based face-to-face interviews, for lactating mothers of age 14 to 45 years and who have at least one child less than three years. Each respondent (mother) was asked to provide a detailed birth history and information about antenatal care. Available medical record was checked. Birth weight was recorded using the metric scale (in grams). The study was conducted at different hospitals, $\mathrm{MCH}$ centers and clinics in Dhaka City, the most densely populated area of Bangladesh, which were selected purposively as the study objective fulfill and the place depending upon communication, availability to the sample and other relevant inclusions and exclusions factors. Study was conducted from January 2014 to December 2016 of the time scheduled and following this period was utilized for questionnaire development, data entry, and analysis. Data were collected from January 2014 to December 2016 in the different areas of Dhaka City. Lactating mother and those whom were agreed to fulfill the questionnaire willingly were included in the study. Respondents, who refused to participate in the study, did not have any child and mothers age of above 45 years old were excluded. Data from children with a missing birth weight, mothers with twin and stillbirths were also excluded from the analysis. A total of 1155 (385 per year) were selected by convenient type of non-probability sampling. Rapport was built before initiation of the study. The permission was taken from the superior authority of specific community clinics and hospitals in Dhaka City. A standard pretested questionnaire was used to obtain the relevant information regarding the socioeconomic information, and information about anthropometric status, vaccination status, information about family planning and antenatal care. Questionnaires were checked each day after interviewing and again these were carefully checked after completion of all data collection to minimize the errors for entering the data set into the computer. The study variables were selected based on epidemiological information, prior studies; several review of the relevant published demographic studies. Education level was defined as less than secondary, secondary, higher education, graduate or above and current occupational status was classified as service, business, part time, and housewife. Income status was classified arbitrarily on the basis of the monthly income of the participants as less than $10000 \mathrm{BDT}, 10000$ to $20000 \mathrm{BDT}, 20000$ to $30000 \mathrm{BDT}, 30000$ to $40000 \mathrm{BDT}, 40000$ to $50000 \mathrm{BDT}, 50000$ to $60000 \mathrm{BDT}$ and greater than $60000 \mathrm{BDT}$ per month. Place of residence was classified as in building, tin shed building, slum. All the statistical analysis and all other data processing were done by using SPSS version 17.0 and Microsoft Excel 2010 windows program. Data were analyzed in term of frequency distribution and percentage. To reveal the association and correlation among different parameters Pearson Chi-square and Pearson correlation tests were used. For tabular, charts and graphical representation Microsoft word and Microsoft excel 2010 were used.

\section{Results}

Socioeconomic Characteristics Participants are given in Table 1a. About $23.5 \%$ family had more than five members, $23.8 \%$ had five members, $29.0 \%$ had four and $23.6 \%$ had three family members. Monthly income of $3.8 \%$ family had less than 10000 BDT followed by $26.1 \%$ family had 10000 to 20000 BDT, $24.2 \%$ had 20000 to 30000 BDT, $9.5 \%$ had 30000 to 40000 BDT, $11.3 \%$ had 40000 to 50000 BDT, $13.2 \%$ had 50000 to 60000 BDT and $11.9 \%$ family had more than 60000 BDT. About $25.3 \%$ families had monthly dietary expenditure less than five thousands followed by $32.6 \%$ had 5000 to $10000 \mathrm{BDT}, 18.9 \%$ had 10000 to $15000 \mathrm{BDT}, 14.3 \%$ had 15000 to $20000 \mathrm{BDT}$ and $8.9 \%$ had above 20000 BDT per month.

Table 1a: Socioeconomic Characteristics of Mother $(n=1155)$.

\begin{tabular}{|c|c|c|}
\hline Number of Family Members & Frequency & Percent \\
\hline Three & 273 & 23.6 \\
\hline Four & 335 & 29 \\
\hline Five & 275 & 23.8 \\
\hline Above & 272 & 23.5 \\
\hline \multicolumn{3}{|l|}{ Family Income (BDT per month) } \\
\hline Less than 10000 & 44 & 3.8 \\
\hline 10000 to 20000 & 302 & 26.1 \\
\hline 20000 to 30000 & 279 & 24.2 \\
\hline 30000 to 40000 & 110 & 9.5 \\
\hline 40000 to 50000 & 131 & 11.3 \\
\hline 50000 to 60000 & 152 & 13.2 \\
\hline Above 60000 & 137 & 11.9 \\
\hline \multicolumn{3}{|l|}{ Dietary Expenditure (BDT per month) } \\
\hline Less than 5000 & 292 & 25.3 \\
\hline 5000 to 10000 & 377 & 32.6 \\
\hline 10000 to 15000 & 218 & 18.9 \\
\hline 15000 to 20000 & 165 & 14.3 \\
\hline Above 20000 & 103 & 8.9 \\
\hline
\end{tabular}

Educational qualification of mother was $46.9 \%$ less than SSC followed by $15.2 \%$ SSC, $22.2 \%$ HSC and $15.8 \%$ graduate or higher. Educational qualification of father was $29.2 \%$ less than SSC followed by $14.8 \%$ SSC, $29.8 \%$ HSC and $26.2 \%$ graduate or higher (Table 1b). Among the participated mother 53.0\% lived in building, $38.0 \%$ in tin shade building and $9.0 \%$ in slum area in Dhaka City. In this study, $66.0 \%$ of the mother was housewife followed by $10.4 \%$ part time worker, $23.0 \%$ full time worker and $0.6 \%$ business woman. On the other hand more than half of the father $(53.9 \%)$ was service holder followed by $31.9 \%$ businessman, $6.3 \%$ rickshaw puller, $2.4 \%$ day labors and $5.5 \%$ other workers. 


\section{Journal of Gynecology and Women's Health}

Table 1b: Socioeconomic Characteristics of Mother (Continue....) $(n=1155)$.

\begin{tabular}{|c|c|c|}
\hline Maternal Education & Frequency & Percent \\
\hline Less than SSC & 542 & 46.9 \\
\hline SSC & 175 & 15.2 \\
\hline HSC & 256 & 22.2 \\
\hline Graduate or Above & 182 & 15.8 \\
\hline \multicolumn{3}{|l|}{ Father's Education } \\
\hline Less than SSC & 337 & 29.2 \\
\hline SSC & 171 & 14.8 \\
\hline HSC & 344 & 29.8 \\
\hline Graduate or Above & 303 & 26.2 \\
\hline \multicolumn{3}{|l|}{ Household Structure } \\
\hline Building & 612 & 53 \\
\hline Tin shade Building & 439 & 38 \\
\hline Slum & 104 & 9 \\
\hline \multicolumn{3}{|l|}{ Occupation of Mother } \\
\hline Service & 266 & 23 \\
\hline Business & 7 & 0.6 \\
\hline Part Time & 120 & 10.4 \\
\hline House Wife & 762 & 66 \\
\hline \multicolumn{3}{|l|}{ Occupation of Father } \\
\hline Service & 623 & 53.9 \\
\hline Business & 368 & 31.9 \\
\hline Rickshaw Puller & 73 & 6.3 \\
\hline Day Labor & 28 & 2.4 \\
\hline Others & 63 & 5.5 \\
\hline
\end{tabular}

The Figure 1 indicates that in this study, most of the children had normal birth weight (72.2\%) and 3.5\%, 20.3\%, and $4.0 \%$ had very low birth weight, low birth weight and overweight respectively.

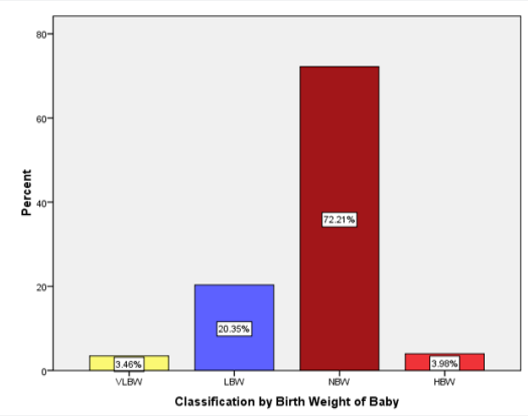

Figure 1: Distribution of Birth Weight of Neonates $(n=1155)$.

In this study, $23.7 \%$ mother faced some kind of mental stress during pregnancy and most of the mother (86.3\%) did not have any mental stress. About $74.1 \%$ mothers got family support and $25.9 \%$ did not get any family support at pregnancy and lactation. Besides $92.6 \%$ mothers were satisfied with their pregnancy and $7.4 \%$ were not satisfied. About $87.7 \%$ mothers consulted with their physician and $12.3 \%$ did not consult with doctor at the initial stage of pregnancy. About $47.1 \%$ mothers had taken TT vaccine during pregnancy followed by $42.5 \%$ took all TT, Rubella and Measles, 5.69\% took only Rubella and 3.48\% did not take any vaccine. Moreover $32.6 \%$ mother went to doctor for three times followed by $23.7 \%$ four times for physical checkup, $14.5 \%$ two times and $3.4 \%$ onetime respectively. About $12.1 \%$ mother did not go to doctor at all (Table 2a).

Table 2a: Information about antenatal care $(n=1155)$.

\begin{tabular}{|c|c|c|}
\hline Variables Related to Antenatal Care & Frequency & Percent \\
\hline \multicolumn{3}{|l|}{ Mental Stress at Pregnancy } \\
\hline Yes & 274 & 23.7 \\
\hline No & 881 & 76.3 \\
\hline \multicolumn{3}{|l|}{ Family Support to Mother } \\
\hline Yes & 856 & 74.1 \\
\hline No & 299 & 25.9 \\
\hline \multicolumn{3}{|l|}{ Satisfaction at Pregnancy } \\
\hline Yes & 1069 & 92.6 \\
\hline No & 86 & 7.4 \\
\hline \multicolumn{3}{|l|}{$\begin{array}{l}\text { Consultation with Doctor from Initial Stage } \\
\text { of Pregnancy }\end{array}$} \\
\hline Yes & 1013 & 87.7 \\
\hline No & 142 & 12.3 \\
\hline \multicolumn{3}{|l|}{ Vaccination Status of Mother } \\
\hline TT & 544 & 47.1 \\
\hline Rubella & 68 & 5.9 \\
\hline Measles & 12 & 1 \\
\hline All TT, Rubella and Measles & 491 & 42.5 \\
\hline None & 40 & 3.5 \\
\hline \multicolumn{3}{|l|}{ Regular Physical Checkup } \\
\hline Yes & 1015 & 87.9 \\
\hline No & 140 & 12.1 \\
\hline \multicolumn{3}{|l|}{ Times of ANC visit } \\
\hline One & 39 & 3.4 \\
\hline Two & 167 & 14.5 \\
\hline Three & 418 & 36.2 \\
\hline Four & 274 & 23.7 \\
\hline Above & 117 & 10.1 \\
\hline None & 140 & 12.1 \\
\hline
\end{tabular}




\section{Journal of Gynecology and Women's Health}

Table 2b: Information about antenatal care(Continue.........) $(n=1155)$.

\begin{tabular}{|c|c|c|}
\hline Variables Related to Antenatal Care & Frequency & Percent \\
\hline \multicolumn{3}{|l|}{ Taking any Medicine during Pregnancy } \\
\hline Yes & 444 & 38.4 \\
\hline No & 711 & 61.6 \\
\hline \multicolumn{3}{|l|}{ Taking any IFA Supplements } \\
\hline Yes & 490 & 42.4 \\
\hline No & 420 & 36.4 \\
\hline Sometimes & 245 & 21.2 \\
\hline \multicolumn{3}{|l|}{ Care Giver } \\
\hline Husband & 471 & 40.8 \\
\hline Mother-in-law & 318 & 27.5 \\
\hline Mother & 291 & 25.2 \\
\hline Others & 75 & 6.5 \\
\hline \multicolumn{3}{|l|}{ Taking Meals Regularly } \\
\hline Yes & 1092 & 94.5 \\
\hline No & 63 & 5.5 \\
\hline \multicolumn{3}{|l|}{ Frequency of Meals per day } \\
\hline Three & 247 & 21.4 \\
\hline Four & 496 & 42.9 \\
\hline Five & 306 & 26.5 \\
\hline Above Five & 106 & 9.2 \\
\hline \multicolumn{3}{|l|}{ Eclampsia } \\
\hline Yes & 123 & 10.6 \\
\hline No & 735 & 63.6 \\
\hline Unknown & 297 & 25.7 \\
\hline
\end{tabular}

About 38.4\% mother took any kind of medicine during their pregnancy and $61.6 \%$ did not take any medicine. Besides $42.4 \%$ mother received free healthcare service such as took iron or Folic Acid supplements regularly, $21.2 \%$ took sometimes and $36.4 \%$ did not receive any iron or calcium supplements from Governmental or Non-Governmental Organization. During pregnancy $40.8 \%$ woman got both mental and physical support and care from their husband and $25.2 \%$ woman took care from their mother in law, 27.5\% took support and care from mother.
On the other hand $6.5 \%$ women took care from others i.e. form maid servants, sister, and sister in laws About 94.5\% mother took meals regularly and only $5.5 \%$ did not take meal regularly. Regarding meal intake $42.9 \%$ mother took meals four times daily followed by $26.5 \%$ five times, $21.4 \%$ three times and $9.2 \%$ above five times in a day during pregnancy. Most of the mother didn't have eclampsia (63.6\%) and $10.6 \%$ respondents had eclampsia at their pregnancy whereas $25.7 \%$ didn't know whether they had eclampsia or not (Table $2 \mathrm{~b}$ ).

Table 3: Association and correlation of birth weight of neonates with antenatal care and socioeconomic factors $(n=1155)$.

\begin{tabular}{|c|c|c|c|}
\hline Variables & r/ $\chi 2$ value & p-value & Comments \\
\hline Maternal Mental Stress & 17.462 & 0.001 & Highly Significant \\
\hline Satisfaction at Pregnancy & 10.38 & 0.016 & Significant \\
\hline Initial ANC Visit during Pregnancy & 22.827 & 0 & Highly Significant \\
\hline Vaccination Status of Mother & 27.519 & 0.007 & Highly Significant \\
\hline Regular Physical Checkup & 15.102 & 0.002 & Highly Significant \\
\hline Times of Physical Checkup & 63.12 & 0 & Highly Significant \\
\hline Taking Medicine at Pregnancy & 7.912 & 0.048 & Significant \\
\hline Taking IFA Supplements & 20.828 & 0.002 & Highly Significant \\
\hline Frequency of Meal per Day & 17.477 & 0.042 & Significant \\
\hline Family Income & 0.192 & 0 & Highly Significant \\
\hline Dietary Expenditure & 0.181 & 0 & Highly Significant \\
\hline
\end{tabular}


Journal of Gynecology and Women's Health

\begin{tabular}{|c|c|c|c|}
\hline Maternal Age & 49 & 0 & Highly Significant \\
\hline Maternal Education & 52.75 & 0 & Highly Significant \\
\hline Father's Education & 41.767 & 0 & Highly Significant \\
\hline Occupation of Mother & 22.004 & 0.009 & Significant \\
\hline Occupation of Father & 20.665 & 0.056 & Not Significant \\
\hline Children Nutritional Status (MUAC) & 26.328 & 0 & Highly Significant \\
\hline
\end{tabular}

Maternal mental stress, satisfaction at pregnancy, initial ANC visit during pregnancy, vaccination status of mother, regular physical checkup, times of physical checkup, taking medicine at pregnancy, taking IFA supplements, frequency of meal per day, maternal age, maternal education, education of father, occupation of father and mother, children nutritional status (MUAC) were significantly associated with birth weight of neonates ( $p$-value<0.05 for all factors). Family income and dietary expenditure had highly significant correlation birth weight of neonates (Table 3).

\section{Discussion}

There are various factors which affect birth weight of neonates. These are complex and interdependent, and are known to influence the birth weight of neonates. Demographic factors pertain to the age, and household structure, socio-economic status (income, education and occupation). The physical factors include the pre-pregnancy weight, maternal height and weight. Antenatal care focuses on the month of initiation as well as the number of visits, vaccination of mother, nutritional care and quality of the care etc. Birth weight is now widely used as an indicator of health status of individuals and populations as it has strong associations with both childhood and adult health. Different studies have revealed that significantly associated risk factors for the birth weight of a newborn vary according to the geographical location and the study population. The mean birth weight observed in our study was 2.759 \pm 0.067 grams. This study found that ANC practices were strongly associated with birth weight of baby. Our study showed that $87 \%$ mother went for one to more than five physical checkup or ANC visit during pregnancy which was strongly associated with parent's education $(\mathrm{p}=0.000<0.05)$ indicates that educated parents had enhanced knowledge of modern health care services and were more concern about their health in pregnancy. This study found that $87.7 \%$ mothers consulted with their physician and $12.3 \%$ did not go for initial ANC visits of pregnancy. The WHO recommends four ANC visits during pregnancy to reduce the various pregnancy related risks. In our study, 33.8\% went four or more times for physical checkup, which is above the average in Bangladesh (21\%) and another study(14.2\%) carried out by Shahjahan et al. [14] but lower than India (56\%), Pakistan (53\%), Indonesia (77\%) and Philippines (69\%) according to WHO report. About 36.2\% mothers went to ANC visit for three times, which is consistent (at least one visit;23\%) with WHO report [15]. In contrast, $14.5 \%$ and $3.4 \%$ mother went to ANC visit for two times and once respectively that are far below the WHO report and $12.1 \%$ mother did not go at all. These are highly significantly associated with birth weight of neonates in Dhaka City. In this study, birth weight showed highly significant association with vaccination $(\mathrm{p}=0.007)$ and $89.6 \%$ took TT vaccine $(47.1 \%$ TT only and $42.5 \%$ all TT, Rubella and Measles) which was higher than National average of Nepal $(63 \%)[16,17]$ and another previous study [18], but lower than a study (99.6) conducted in India [19]. Besides 5.69\% took only Rubella and only $3.48 \%$ did not take any vaccine; indicate that maternal vaccination is very important to keep them healthy during pregnancy, and strong determinant of birth weight of children. The study also revealed a weak association with medicine intake $(\mathrm{p}=0.048)$ and $38.4 \%$ mother has taken any kind of medicine during their pregnancy and $61.6 \%$ did not take any medicine. Only $42.4 \%$ mother received free healthcare service such as took iron or Folic Acid supplements regularly, which is lower than (50\%) IFA intake in India [20]. Moreover 21.2\% took sometimes and $36.4 \%$ did not receive any iron or folic acid supplements and significantly associated with paternal education $(\mathrm{p}=0.000)$ and highly significantly associated with birth weight $(\mathrm{p}=0.002)$. The proportion of LBW among women of low economic class was higher when compared to those in high economic status with significant correlation ( $\mathrm{p}=0.000)$, which was similar to two previous findings $[21,22]$. Limited study areas were selected. No fund was available for the research. Respondents were shy to provide real information in many cases. Much biochemical information is not available in many cases.

\section{Conclusion}

In a nutshell it can be concluded that several antenatal care factors such as maternal mental stress, satisfaction at pregnancy, initial ANC visit during pregnancy, vaccination status of mother, regular physical checkup, times of physical checkup, taking medicine at pregnancy, taking IFA supplements, frequency of meal per day were significantly associated with birth weight of neonates. In case of socioeconomic determinants like maternal age, maternal education, education of father, occupation of father and mother, were significantly associated with birth weight of neonates. Family income and dietary expenditure had highly significant correlation birth weight of neonates.

\section{Acknowledgement}

We thank all the women who participated in our study as well as the authorities of different MCH Center, Clinic and Hospital in Dhaka City; data collectors and supervisor for their unreserved cooperation. 


\section{References}

1. United Nations Children's Fund (2017) Undernourishment in the womb can lead to diminished potential and predispose infants to early death 2014 .

2. WHO (2010) International statistical classification of diseases and related health problems (ICD-10. 10ed). World Health Organization, Geneva, Switzerland.

3. Kramer MS (1987) Determinants of low birth weight: methodological assessment and meta-analysis. Bull World Health Organ 65(5): 663737.

4. Eichenwald EC, Stark AR (2008) Management and outcomes of very low birth weight. N Engl J Med 358(16): 1700-1711.

5. Islam MM (2015) Increasing incidence of infants with low birth weight in Oman. Sultan Qaboos Univ Med J 15(2): e177-183.

6. Richard M, Hardy R, Kuh D, Wadsworth ME (2001) Birth weight and cognitive function in the British 1946 birth cohort: longitudinal population based study. Br Med J 322(7280): 199-204.

7. Hodek JM, von der Schulenburg JM, Mittendorf T (2011) Measuring economic consequences of preterm birth: methodological recommendations for the evaluation of personal burden on children and their caregivers. Health Econ Rev 1(1): 6.

8. Barker DJ, Forsén T, Uutela A, Osmond C, Eriksson JG (2001) Size at birth and resilience to effects of poor living conditions in adult life: longitudinal study. BMJ 323(7324): 1273-1276.

9. Dasgupta A, Basu R (2011) Determinants of low birth weight in a Block of Hooghly, West Bengal: a multivariate analysis. Int J Biol Med Res 2(4): 838-842.

10. Deshpande JD, Phalke DB, Bangal VB, Peeyuusha D, Sushen B (2011) Maternal risk factors for low birth weight neonates: a hospital based case control study in rural area of western maharashtra, India. Natl J Community Med 2(3): 394-398.

11. Nobile CG, Raffaele G, Altomare C, Pavia M (2007) Influence of maternal and social factors as predictors of low birth weight in Italy. BMC Public Health 7: 192.
12. Sebayang SK, Dibley MJ, Kelly PJ, Shankar AV, Shankar AH, et al. (2012) Determinants of low birth weight, small-for-gestational-age and preterm birth in Lombak, Indonesia: analysis of the birth weight cohort of the SUMMIT trial. Trop Med Int Health 17(8): 938-950.

13. Parker JD, Schoendorf KC, Kiely JL (1994) Associations between measures of socioeconomic status and low birth weight, small for gestational age, and premature delivery in the United States. Ann Epidemiol 4(4): 271-278.

14. Shahjahan M, Chowdhury HA, Al-Hadhrami AY, Harun GD (2017) Antenatal and postnatal care practices among mothers in rural Bangladesh: Acommunity based cross-sectional study. Midwifery 52: 42-48.

15. WHO, UNICEF (2003) Antenatal care in developing countries: promises, achievements and missed opportunities: An analysis of trends, levels and differentials, 1990-2001. World Health Organization, Geneva, Switzerland.

16. (2007) Ministry of Health and Population (MOHP), New ERA, Kathmandu, Nepal and Macro International Inc., Calverton, Maryland, USA. Demographic and Health Survey, Nepal, pp. 135-155.

17. Devkota B (1994) A study of knowledge Attitude and Practices of mother and Maternal and Child Health Care at Pandurung Village 1994. Unpublished Master's Thesis, Faculty of Education, TU, Kirtipur, Nepal.

18. Pradhan A (2005) Situation of antenatal care and delivery practices. Kathmandu Univ Med J 3(3): 260-270.

19. Jalina L, Usha Devi T, Jina P, Salona M, Sanayaima Devi H (2013) Knowledge and Practice of Ante-natal Care in Urban Area. Indian Medical Gazette 2013: 101.

20. IIPS (2003) National Family Health Survey-India, 1998-99. International Institute of Population Studies, Bombay, India.

21. Kalanda B, Verhoeff F, le Cessie S, Brabin J (2009) Low birth weight and fetal anaemia as risk factors for infant morbidity in rural Malawi. Malawi Med J 21(2): 69-74.

22. Hirve SS, Ganatra BR (1994) Determinants of low birth weight: a community based prospective cohort study. Indian Pediatr 31(10):

\section{Your next submission with Juniper Publishers will reach you the below assets}

- Quality Editorial service

- Swift Peer Review

- Reprints availability

- E-prints Service

- Manuscript Podcast for convenient understanding

- Global attainment for your research

- Manuscript accessibility in different formats

( Pdf, E-pub, Full Text, Audio)

- Unceasing customer service

Track the below URL for one-step submission https://juniperpublishers.com/online-submission.php 